\title{
VIDA, SAÚDE E TRABALHO: DIALOGANDO SOBRE QUALIDADE DE VIDA NO TRABALHO EM UM CENÁRIO DE PRECARIZAÇÃO
}

\author{
LIFE, HEALTH AND WORK: A DISCUSSION ABOUT QUALITY OF WORK LIFE IN A SCENARIO \\ OF PRECARIOUSNESS
}

Milton Athayde
Jussara Brito $^{2}$

Resumo Com este artigo, pretendemos dialogar com o texto elaborado por Padilha, base para o debate neste número da revista, tendo como desafio discutir algumas das questões que emergem do artigo em foco. Neste mesmo movimento, aproveitamos para assinalar algumas de nossas posições a respeito. Iniciamos colocando em pauta a urgência de uma perspectiva crítica e afirmativa da potência da vida frente aos impedimentos e constrangimentos tão frequentes e poderosos (como o processo de precarização do trabalho em curso), tema de nosso segundo tópico. Concluindo o diálogo, colocamos sinteticamente em foco o processo de emergência da questão da 'Qualidade de Vida' e posteriormente a da chamada 'Qualidade de Vida no Trabalho', concluindo por discutir do que se trata.

Palavras-chave trabalho; capitalismo; precarização;

Abstract With this article, we intend to discuss the text written by Padilha, a basis for debate on this issue of the magazine, and embrace the challenge of discussing some of the issues that emerge from the referred article. In this same movement we took the opportunity to point out some of our positions on the issue. We began by prioritizing the urgent need for a critical and affirmative perspective of the power of life in relation to the very frequent and powerful impediments and constraints (such as the process of turning the work in progress precarious), the subject of our second topic. To conclude the discussion, we briefly focus on the process of emergence of the issue of 'Quality of Life' and then the so-called 'Quality of Work Life' (QWL), and finally discussing what it is. Keywords fiscal federalism, health policy. 


\section{Uma perspectiva crítica quanto ao viver e suas transformações possíveis}

Tomamos como ponto de partida para conversar a ideia principal que a autora nos indica já em seu resumo:

as políticas de QVT adotadas em empresas podem aliviar momentaneamente alguns sintomas, mas não ferem as causas estruturais dos problemas. A humanização da gestão da força de trabalho pode ser uma encenação necessária no interior das organizações, mas não deve ser vista como solução para os males do trabalho (Padilha, 2009, 549).

Sua linha de raciocínio em torno da questão, conforme enuncia, busca orientar-se por uma perspectiva crítica. Como seus leitores, em diálogo com o texto, dizemos: então a autora situa-se junto a toda uma linhagem materialista no pensamento ocidental, no interior da qual encontramos o esforço analítico de pensadores como Lucrécio, Espinoza, Marx. Seguramente Marx é uma referência, e em grande parte de sua obra buscou operar uma 'crítica a...', um extraordinário esforço para colaborar na produção da crise, 'rachando' o que se apresenta como um bloco naturalizado de 'já-dados'.

Nesta linhagem materialista e histórica, plural, rica inclusive em polêmicas e correntes controversas, encontramos um modo de análise que ao se deparar com impasses e falsas questões, as desborda, inventando passagens, explorando-as em sua potência afirmativa da vida. É nesta direção que entendemos a pergunta formulada por Zarifian (1995b): por que não explorar o campo de possíveis 3 contido no próprio movimento do real, afirmando o que neste curso seja indicador de mudanças consistentes? Sim, pois a possibilidade de transformação social reside no próprio movimento do real. Daí a tarefa de captar o que é indicador das transformações, do devir, dos desvios e bifurcações, aquilo que não somente prefigura, mas figura uma outra sociedade/sociabilidade. Ou seja, um campo de possíveis está sempre presente, mesmo que no infinitesimal (Schwartz, 1988), em estado emergente, mesmo que frágeis, mascarados pelas evidências dominantes.

Dado o caráter sempre inacabado da sociedade, embora seja útil descrever exaustivamente o real e identificar as regulações e as regras sociais que lhe correspondem, o encaminhamento mais fértil exige captar a abertura para o que, como evento (Zarifian, 1995a), rompe o habitual, para aquilo que em suas bifurcações e desvios pode estar compondo novas formas societárias e relacionais. As situações de trabalho, como espaço-tempo de problemas, de dramáticas de uso de si, são matrizes de variabilidade, de história, dada a emergência de eventos (acontecimentos, infidelidades do meio), recentrando o meio como seu meio (Canguilhem, 2001), quebrando os ritmos sequenciais dos hábitos, do que é antecipável na vida. Exige-se então lidar com tais eventos, é 
preciso fazer (micro) escolhas, apela-se a usos de si (não apenas execução de ordens, mas a tensão dos usos de si, por/para si mesmo pelos/para outrem), gerando dramáticas - tensas convocações individuais e/ou coletivas. Neste mesmo movimento, tais reações produzem novos acontecimentos, transformando incessantemente a relação com o meio e entre as pessoas (Schwartz e Durrive, 2008).

Ou seja, frente às crises o questionamento heurístico parece-nos ser: que outras relações sociais estão em vias de surgir (mesmo se relações minoritáras e dominadas), representativas de um devir diverso (não anti ou pós ${ }^{4}$ )? Como assinala Zarifian, é destes possiveis, de sua abertura, que vêm uma parte importante tanto do sofrimento patogênico, quanto do potencial de revolta contra as relações dominantes. Ou seja, este potencial, este possível diverso de algum modo já existe, na própria constituição do real. Nas crises contemporâneas, desde o final dos anos 60, mudanças na organização da produção e na composição da classe trabalhadora 5 configuram novas condições e conjunturas, abrindo novas oportunidades de luta por outra sociabilidade.

Mas a complexidade que então se apresenta pode nos confundir. O viver e o trabalhar, considerando seu caráter sempre inacabado e enigmático, extrapolam nossa capacidade de inteiramente compreendê-los, exigindo uma perspectiva de diálogo sinérgico entre saberes, incorporando ao empreendimento de co-análise os protagonistas da atividade e os saberes engendrados na atividade cotidiana. A complexidade deste encontro exibe culturas e inculturas recíprocas, provoca desconforto intelectual e exige humildade epistêmica, nas palavras de Schwartz (2000). A orientação ergológica, operando à lupa, com o ponto de vista da atividade (Schwartz e Durrive, 2009), parece-nos então incontornável, caso busquemos compreender transformar a vida, o trabalho e os humanos em sua concretude (síntese de múltiplas determinações e relações na sociedade em que se vive).

\section{O capital precariza, encena e delira?}

Já no título a autora aponta para um cenário de precarização na ordem do capital, em que a rubrica QVT encena a seu ver como uma panaceia delirante.

Mas o capital, desde sua emergência, só pode funcionar ampliando os limites territoriais e populacionais, desterritorializando. Sendo sua tendência incontrolável a de expandir-se, seu limite é o próprio capital, neste sentido o capital delira. Passado o susto com o adjetivo, vamos ao substantivo, pois a autora convida à cena da argumentação uma figura mítica, afirmando QVT como uma panaceia delirante. Na mitologia grega, Asclépio6 é o deus da medicina e da cura. Dentre seus filhos encontrava-se Higia, deusa da higiene (ou da saúde pública), sendo associada à prevenção da doença e à manutenção da boa saúde. Outra 
filha era Panacéia, deusa da farmácia, ou da cura. Mas é interessante que o debate no campo da Saúde Pública, no esforço de ir além da contradição dicotômica (de origem aristotélica) entre promoção de saúde (Higia) e cura (Panaceia), resgata-se um terceiro termo, incluindo Asclépio na reflexão, que não substitui nem é substituído pelas duas. Ampliemos a polifonia da cena, com o diálogo entre Esculápio, Higia e Panaceia, escapando ao reducionismo panacéico de qualquer pretensa cura ou 'solução para os males do trabalho'.

Reiteremos que o movimento do capital flui na (re)produção sempre ampliada de valor (de capital). Conversemos então sobre ideologia, cujas práticas exigem análise, para além da 'falsa consciência', do puro mascaramento, ilusão ou ocultamento, mero falseamento do real, como se fosse simplesmente uma enganação a ser eliminada. Entendemos que não se trata de mecanismos ocultos pela aparência, a serem des-cobertos em sua essência.

As ideologias, como práticas concretas, têm como função primordial, nas palavras de Althusser, constituir indivíduos em sujeitos. Elas existem materialmente nas sociedades de exploração-dominação em aparelhos de Estado. Ou seja, não se trata do mito rousseauniano da desigualdade, em que os ricos convencem os pobres a viver uma servidão com se fosse a sua liberdade. A função da ideologia dominante (que hoje, para muitos, seria a neoliberal) não é apenas dominar a classe explorada, ela é ativa sobre a própria classe dominante: os agentes da burguesia precisam antes estar convencidos das ideias (como a de liberdade, do trabalho livre), que em seguida irão a outros buscar convencer (como a de que o trabalho - tomado de forma abstrata, genérica - dignifica o homem, de que o tempo é útil etc.). Ela se adapta às suas próprias condições reais de existência. Se QVT se caracteriza como uma ideologia, na forma de uma 'panaceia delirante', há que investigar quais suas condições de proveniência e emergência, como funciona (em sua generalidade e singularidade).

Consideremos que os princípios do Taylorismo (em torno da busca da maior produtividade possível) foram incorporados e superados pelo Fordismo (propagando-se pelo extrafabril, estabelecendo o compromisso fordista com base keynesiana). Entretanto, após o círculo virtuoso dos trinta anos 'gloriosos' pós-segunda guerra, esboroou-se em crises e revelou seu esgotamento, daí a busca de alternativas, com base em inovações tecnológicas e organizacionais. Um processo atravessado por paradoxos e continuidades, inclusive as mais absurdas, como no caso da formação social brasileira, com a presença do trabalho escravo. Neste cenário complexo de crises e paradoxos, encontramos também em cena o que vem sendo chamado de precarização ${ }^{7}$ (do emprego e do trabalho). Temos que tomar cuidado, pois ela não pode ser apreendida como um fim em si, nem é explicável pela exploração contemporânea, pois mais remete a práticas características de acumulação primitiva de capital. Assim como o Estado capitalista se aparelha ideologicamente e sempre que necessário apela ao aparelho repressivo, à polícia usada para a ação criminosa, sempre que 
necessário ao movimento do capital o mundo da produção é brutalmente precarizado, mesmo que certamente não seja esta a melhor forma de alcance de produtividade e qualidade a médio e longo prazos.

A ideia de que com a precarização o capital buscaria e alcançaria maior produtividade não se sustenta, caso se entenda que a busca da maior produtividade possível envolve combinar aumento de produção com o menor custo, inclusive humano. Poderíamos talvez dizer que se busca através dela a modalidade de extorsão de mais-valia possível nessa conjuntura de crise. Crise que é também de nossa capacidade de conhecimento e compreensão do que está em curso. A terceirização, por exemplo, é muitas vezes colocada no mesmo saco da precarização, mas salvo engano é algo diverso, ao menos se a consideramos a partir do que se engendrou no Japão pós-guerra: dada a fragilidade do capitalismo de então naquele país, buscou-se (com o financiamento internacional disponibilizado) avançar através de uma estratégia de parceria em cada cadeia produtiva, sendo o terceiro um legítimo outro neste contexto, um parceiro qualificado em seu campo específico. O que encontramos no Brasil etiquetado por muitos críticos como 'terceirização' é outra estratégia: anulação da alteridade, violência, precarização não apenas no plano jurídico-político do contrato de trabalho (o salariato e o emprego 'flexibilizados'). O que se descobriu ao longo deste processo (que desembocou no que amiúde vem sendo designado por pós-fordismo ou toyotismo ${ }^{8}$ ) é que produtividade \& qualidade (sábia exigência societária que volta à cena no contemporâneo, parcialmente subordinadas ao capital) têm que ser perseguidas em conjunto. A produção capitalista deparou-se com a percepção (distorcida pela financeirização) de que não se trata apenas de qualidade do produto, inclusive porque ela só pode ser garantida pelo controle de qualidade no processo de produção (não só no processo de trabalho, mas nas relações sociais de produção), revelando o quanto se está na dependência dos operadores efetivos deste processo, de sua implicação, automobilização, das relações estabelecidas com eles e entre eles. Ou seja, um campo de forças profundamente contraditório, a partir do qual aberturas poderiam ser possíveis. ${ }^{9}$ Porém, quando a busca de produtividade vira aumento de produção e se desgarra da garantia de qualidade, um quadro distorcido se configura, do ponto de vista mesmo do capital.

Ou seja, na medida em que a estratégia fordista já não mais se revela sustentável, na busca por alternativas o capital vem engendrando uma máquina produtiva em que as novas tecnologias e formas de organização do trabalho pertinentes à busca de produtividade e qualidade são dependentes da implicação 'subjetiva' e da inventividade (mesmo que no infinitesimal) daqueles que trabalham. É claro que não se trata de um capital domesticado, buscando 'beneficiar'10 os trabalhadores, mas uma forma de movimento do capital, enquanto relação social eivada de antagonismos paradoxais. 
Na verdade, ainda precisamos conhecer e melhor compreender que processos são estes e como se configuram em cada mundo do trabalho, em cada conjuntura específica. Que outras sinergias são estas que estão em curso entre os processos de trabalho, subjetivação e saúde-doença? Os textos-denúncia que temos são necessários, mas não suficientes. Por outro lado, um dos equívocos que se instituiu largamente é de que haveria um taylorismo-fordismo que operaria com base na anulação sociocognitiva-afetiva no trabalho. Em geral se faz tal afirmação de forma absoluta e peremptória; algumas vezes encontra-se ao menos uma fértil ambigüidade na argumentação, como temos no texto de Alves (2005), publicado nesta mesma revista. Em um primeiro momento, a respeito da mundialização do capital, mobilizando Gramsci, o autor afirma que

ela se distingue da forma dominante no sistema taylorista-fordista, que tendia a 'separar' corpo e mente. Como salientava Gramsci, com argúcia, sob o fordismo 'o cérebro está livre para outras ocupações', enquanto o corpo é capturado pelas prescrições mecanizadas (Gramsci, 1984). Esta relação problemática entre corpo e mente é um dos elementos de crise do taylorismo-fordismo' (Alves, 2005, p. 411).

Páginas adiante (Alves, 2005, p. 417), mobilizando o mesmo Gramsci, diz o autor que "não é que sob o fordismo o operário na linha de montagem convencional não pensasse. Pelo contrário, como salientou Gramsci, sob o fordismo

(...) o operário continua 'infelizmente' homem e, inclusive (...) durante o trabalho, pensa demais ou, pelo menos, tem muito mais possibilidade de pensar, principalmente depois de ter superado a crise de adaptação. Ele não só pensa, mas o fato de que o trabalho não lhe dá satisfações imediatas, quando compreende que se pretende transformá-lo num gorila domesticado, pode levá-lo a um curso de pensamentos pouco conformistas" (Gramsci, 1984, p. 378).

Ou seja, estava também presente na análise de Gramsci o que os precursores da Psicologia Ergonômica na Bélgica e França também descobriam e que a Ergonomia da Atividade veio dar consistência e esclarecer: a distância entre 'trabalho prescrito' e 'trabalho real', ou o que em seguida vai-se conceituar por tarefa e atividade. Uma dinâmica que a Ergologia (na linhagem de Canguilhem e outros) conceitua por debate de normas, envolvendo a relação entre normas antecedentes (registro 1) e renormatização (registro 2). Toma aí nobreza uma potência ativa, normativa, que é característica do vivente, e que na perspectiva da Ergologia (Schwartz, 2000; 2009), no caso do humano é operada por 'entidades coletivas relativamente pertinentes', destacando-se aí o 'corpo-si'. Uma dinâmica psicossocial que toda uma linhagem clínica do trabalho, na perspectiva da atividade, vem esclarecendo. A Psicodinâmica do Trabalho (Dejours, 
2005; 2009) fala em sistemas defensivos frente ao sofrimento patogênico, caminho criador em direção ao prazer por processos sublimatórios e pela dinâmica do reconhecimento, o real do trabalho, atividade subjetivante, regras e lingua de ofício, inteligência e sabedoria do corpo, da prática. A Clínica do Trabalho (Clot, 2006) vem abordando esta dinâmica com os conceitos de atividade possível e impossivel, poder de agir de coletivos de trabalho, zona de desenvolvimento potencial, real da atividade.

Ou seja, temos hoje toda uma caixa de ferramentas teórico-metodológica que pode colaborar decisivamente para avançar além de afirmações peremptórias e genéricas, considerando as diferenças entre trabalho abstrato e concreto, privilegiando este último na análise. Já sabemos suficientemente o quanto tudo que é pertinente à vida, à saúde e ao trabalho envolve sempre mudanças, revelando-se em seu inacabamento um campo enigmático e complexo. A perspectiva ergológica nos orienta o quanto a exigência epistêmica, ligada ao objetivo de conhecer, precisa dialogar com a exigência transformativa, ligada ao agir que modifica o estado das coisas. Mas conhecimento e ação não são pares dicotômicos de opostos, na atividade humana (como na de trabalho), conjugam-se o transformativo e o epistêmico. A perspectiva ergológica, ao conceber a atividade como debate de normas e valores, estimula a fértil confrontação dos saberes entre si, seja da experiência, da prática, seja do conhecimento científico (também aqui, confrontação entre as disciplinas e entre suas correntes internas), propiciando o desenvolvimento de todos. Mas com o vocábulo confrontação não se faz menção a briga ou comparação, e sim ao diálogo crítico e sinérgico entre aqueles dois polos de sapiência, o que supõe disponibilidade dos parceiros que aí operam para a controvérsia. Schwartz (1988), analisando criticamente a experimentação extraordinária de Oddone e parceiros (1981), que gerou o Modelo Operário de luta pela saúde, o MOI (criando um dispositivo que eles denominavam Comunidade Científica Ampliada), entendeu que é fundamental a presença de um terceiro polo (ético-epistêmico) a fim de fazer trabalhar os dois primeiros de modo cooperativo, dessa forma sendo possível produzir um saber inédito a propósito da atividade humana. Ao novo paradigma de desenvolvimento de saberes Schwartz (1996) denominou 'dispositivo dinâmico de três polos' (DD3P).

Neste processo tem ficado cada vez mais claro o quanto a abordagem clínica é importante, a presença com o olhar à lupa nos meios de trabalho, acompanhando as situações concretas, dialogando criticamente com os protagonistas da atividade de trabalho em análise. A produção linguageira (também ela atividade na atividade) toma então destaque, não só aquela que se dá durante o trabalho, como a que pode se desenvolver sobre o trabalho realizado (o que se pode dizer do que foi dito e o que se pode fazer com o que se disse). Tendo-se clareza da opacidade do trabalhar, da ingenuidade que seria tomar depoimentos como verdade das coisas, destaca-se a importância de métodos indiretos 
(na tradição de Vigotski), a partir do que a Ergonomia já vinha explorando como confrontação, seja com a técnica que o MOI criou de 'instruções ao sósia' (Oddone et al., 1981), seja com técnicas de autoconfrontação simples ou cruzada, que vêm sendo desenvolvidas por Clot (2006) e Faïta (2009).

Daí sugerirmos que para melhor entendermos esta ou aquela estratégia organizacional em curso na produção capitalista, esta ou aquela prática ideológica, é importante verificar como elas revelam-se nas situações concretas de trabalho. Além disso, tal resposta pode ter outra riqueza e maior potência transformadora na medida em que a investigação passe por diversas e diferentes validações, inclusive junto aos protagonistas da atividade em análise. Caso contrário, com frequência vamos nos limitar à esgrima de afirmações abstratas, fundadas ou não em legitimações de 'bases empíricas'.

\section{QVT - do que se trata?}

O título acima remete à exigência de melhor compreendê-lo (QVT), considerando seu caráter multifacético e a singularidade dos meios de trabalho e das situações concretas.

Antes da emergência do movimento autodenominado Qualidade de Vida no Trabalho (QVT), é preciso que em sua genealogia registremos a existência de um movimento anterior - sanitário, e não exclusivamente médico - pela Qualidade de Vida (QV). Seidl e Zannon (2004) assinalam indícios de que o termo teria surgido na literatura médica da década de 30 do século passado e que

já em meados da década de 70, Campbell (1976, apud Awad \& Voruganti 8, p. 558) tentou explicitar as dificuldades que cercavam a conceituação do termo qualidade de vida: 'qualidade de vida é uma vaga e etérea entidade, algo sobre a qual muita gente fala, mas que ninguém sabe claramente o que é' (Seidl e Zannon, 2004, p. 580).

Mas o construto apresenta duas formulações, uma relacionada à saúde, referida ao impacto da enfermidade ou do agravo na qualidade de vida), e outra, mais genérica, de influência sociológica. Entende-se que a partir do início da década de 1990 chegou-se a um consenso quanto a dois aspectos relevantes do conceito de qualidade de vida: multidimensionalidade e subjetividade. Quanto à subjetividade, considera-se ter havido um avanço, pois se até então a QV era avaliada por um observador externo (em geral, um profissional de saúde), a partir daí entende-se que ela só pode ser avaliada pela própria pessoa. Passa a ter um papel central a percepção da própria pessoa sobre seu estado de saúde e sobre os aspectos não-médicos do seu contexto de vida. Uma abordagem que pode ser encontrada na concepção de saúde de Canguilhem (2006). Quanto à multidimensionalidade, o consenso a que se chegou é de que QV é um construto 
composto por diferentes dimensões, gerando pesquisas empíricas com métodos qualitativos e quantitativos.

QVT emerge posteriormente. Procurando situá-la historicamente, a autora do texto-guia nos afirma que em sua emergência (pós-guerra, entre as décadas de 1950 a 1970) predominava uma "Psicologia Organizacional fortemente behaviorista". Segundo a autora, é quando "na Inglaterra, surge o primeiro modelo de QVT, com base nos estudos de Eric Trist que trabalhava na perspectiva da Escola Sociotécnica, do Tavistock Institute of Human Relations" (Padilha, 2009, p. 551).

À diferença de uma abordagem behaviorista capturada ou voluntariamente servil ao poder do capital, a abordagem Sociotécnica já vinha - durante a guerra - fazendo suas experimentações, sob demanda do governo britânico, em função da economia de guerra contra o nazismo. O Instituto Tavistock originário era um organismo de formação e práticas de saúde, inclusive no campo da saúde mental, de base psicanalítica e reconhecimento internacional por sua excelência. Os nomes de Melanie Klein, Bion, Winnicott seriam suficientes para assinalar tanto a originalidade de sua produção quanto sua autonomia, mesmo em relação à hegemonia impetrada por Freud na instituição da psicanálise. Fruto do sucesso de suas intervenções durante a Segunda Guerra no campo social, tiveram o apoio para uma ampliação do Instituto, voltando-se para as questões do trabalho e das 'relações humanas'. Neste empreendimento constituíram um grupo de alto nível, juntando não só Trist como Emery, Jaques e outros. Suas experimentações, em empresas públicas e privadas, não só na Inglaterra como em outros países da Europa e nos EUA, tiveram sucesso e levaram a uma nova construção teórica e metodológica. No pós-guerra foram contratados para uma proposição de uma 'democracia industrial' na Noruega, colaboraram na construção do 'modelo sueco', na montagem de automóveis Volvo (a proposta de 'semiautonomia') etc. Enfim, se QVT remete a esta abordagem, tem suas fontes originárias em um rico patrimônio. Assim como a Ergonomia da Atividade, esta corrente da Psicologia do Trabalho \& Organizacional buscou virar o jogo, mesmo que dentro dos limites do capital, adaptando o trabalho ao homem, buscando compreender o modo de ser e trabalhar dos viventes humanos. E, neste sentido, ambas podem ser consideradas muito importantes, do ponto de vista da transformação social.

$\mathrm{O}$ vínculo estreito entre precarização e QVT pode, por um lado, dar maior consistência e concretude à análise. Ora, como já foi apontado por autores como Lacaz (2000) e Ferreira (2006), certamente sua utilização em tais contextos é de fato abertamente manipulatória. Mas restringir-se a este vínculo pode contaminar a análise e empobrecê-la na tão importante capacidade de explorar o campo de possíveis contido no próprio movimento do real. 


\section{Notas}

1 Docente da Universidade do Estado do Rio de Janeiro (Uerj), Instituto de Psicologia, Programa de Pós-Graduação em Psicologia Social. Coordenador do Grupo de Pesquisa Actividade/CNPq. Pós-doutorado em Ergologia na Université d'Aix-en-Provence (França, 2002-2004). Doutor em Engenharia de Produção/Gerência da Produção/Ergonomia pela Coppe/Universidade Federal do Rio de Janeiro (UFRJ). < athayde.milton@gmail.com> Correspondência: Rua São Clemente, 103, casa 28, ap. 101, Rio de Janeiro, Brasil, CEP 20550-090.

2 Pesquisadora Titular da Fundação Oswaldo Cruz, Escola Nacional de Saúde Pública Sergio Arouca, Centro de Estudos da Saúde do Trabalhador e Ecologia Humana. Coordenadora do Grupo de Pesquisa Pistas/CNPq. Pós-doutorado em Ergologia na Université d'Aix-en-Provence (França, 2002-2004). Doutora em Saúde Pública pela Escola Nacional de Saúde Pública, Fundação Oswaldo Cruz (ENSP/Fiocruz). <jussaradebrito@gmail.com>

3 Os pontos de tensão, os nós esquivos onde relações contraditórias se estabelecem, pois que os nós - em suas estranhezas - são muito mais importantes que os laços.

4 Por exemplo, diverso do taylorismo, e não anti ou pós.

5 Utilizemos criticamente este conceito, pois ele exige ser colocado em análise.

6 Esculápio, em latim, como é mais conhecido entre nós.

7 O trabalho e o emprego não podem ser denominados precários, eles vêm sendo precarizados.

8 Visto por alguns como 'momento predominante', expressão superior da racionalização do capitalismo global e do desenvolvimento do regime de acumulação flexível, nos loci mais dinâmicos da acumulação.

9 Como afirma Marx no 18 Brumário de Luiz Bonaparte: “os homens fazem sua própria história, mas não a fazem como querem; não a fazem sob circunstâncias de sua escolha, e sim sob aquelas com que se defrontam diretamente, ligadas e transmitidas pelo passado" (Marx, 1968, p. 15).

10 O próprio vocábulo 'benefício' faz parte da produção discursiva do Estado getulista, contido na lógica CLT. 


\section{Referências}

ALVES, Giovanni. Trabalho, corpo e subjetividade: toyotismo e formas de precariedade no capitalismo global. Trabalho, Educação e Saúde, v. 3 n. 2, p. 409- 428.

CANGUILHEM, George. O normal e o patológico. 6. ed. Rio de Janeiro: Forense Universitária, 2006.

Meios e normas do homem no trabalho. Revista Proposições, v. 12, n. 2-3, p. 109-121, 2001.

CLOT, Yves. A função psicológica do trabalho. Petrópolis: Vozes, 2006.

DEJOURS, Christophe. Christophe Dejours: da psicopatologia à psicodinâmica do trabalho. 2. ed. Rio de Janeiro/Brasília: Ed. Fiocruz/ Paralelo 15, 2009.

FGV, 2005.

O fator humano. 5. ed. Rio de Janeiro:

FAITA, Daniel. Sur la Méthode d'Auto-Confrontation (MAC). In : FAITA, Daniel e MAGGI, Bruno. Un débat en analyse du travail: Deux méthodes en synergie dans l'étude d'une situation d'enseignement. Toulouse: Octarès, 2009.

MARX, KARL. 18 Brumário de Luiz Bonaparte. São Paulo: Escriba, 1968.

ODDONE, Ivar ; RE, Alessandra ; BRIANTI, Giani. Redécouvrir l'expérience ouvrière. Paris: Eds. Sociales, 1981.
SCHWARTZ, Yves. Le paradigme ergologique ou un métier de Philosophe. Toulouse: Octarès, 2000 .

Expérience et connaissance du travail. Paris: Messidor/Eds. Sociales, 1988.

SCHWARTZ, Yves; DURRIVE, Louis. Trabalho e ergologia: conversas sobre a atividade humana. 2. ed.rev. e ampl. Niterói: EdUFF, 2009.

Glossário de ergologia. Laboreal, v. IV, n. 1, p. 23-28, 2008. Disponível em: $<$ http://laboreal.up.pt/media/artigos/166/2328pt.pdf>. Acesso em: 5 nov. 2009.

SEIDL, E.M.F. e ZANNON, C.M.L. Qualidade de vida e saúde: aspectos conceituais e metodológicos. Cadernos de Saúde Pública, Rio de Janeiro, v. 20, n. 2, p. 580-588, 2004.

PADILHA, Valquíria. Qualidade de Vida no Trabalho num contexto de precarização: a panaceia delirante. Trabalho, Educação e Saúde, Rio de Janeiro, p. 549-563, nov. 2009/fev. 2010.

ZARIFIAN, Philipe. Le travail et l'événement: Essai sociologique sur le travail industriel à l'époque actuelle. Paris: Harmattan, 1995a.

Novas formas de organização e modelo da competência na indústria francesa. In: Workshop: implementação de novas formas de organização do trabalho, Epusp, São Paulo, 15-18 ago., 1995b. 